\section{Unifying science}

\section{Knut Schmidt-Nielsen}

The Logic of Life: The Challenge of Integrative Physiology. Edited by C. A. R. Boyd and D. Noble. Oxford University Press: 1993. Pp. 226. £8.95, \$14.95.

How can the avalanche of information about molecular biology be put together into a conceptually coherent picture? In their introductory essay to this book, Noble and Boyd provide an answer, they conclude that "there can be no doubt that physiology ... will be indispensable to the proper interpretation of molecular biology itself".

They compare the feeling we get from the astonishing progress in molecular biology today to the excitement in the middle of the nineteenth century when German organic chemists forged ahead with spectacular discoveries of 'organic' substances in 'non-living' test-tube environments. This analogy implies that the role of molecular biology is in question; they answer that without an understanding of the overall logic of higher-level systems, the lower-level detail becomes mere cataloguing of information.

Noble and Boyd sent their essay to a number of eminent biologists, asking them to respond in whatever way was appropriate to their own field. This intellectual challenge resulted in eight essays that represent the wide spectrum of biological thinking today, yet, in its own way, each illuminates the importance of the organism. With the editors' introductory essay and a foreword by the Nobel laureate Sir James Black, these essays form the chapters of this small volume published in celebration of the 1993 International Congress of Physiology.
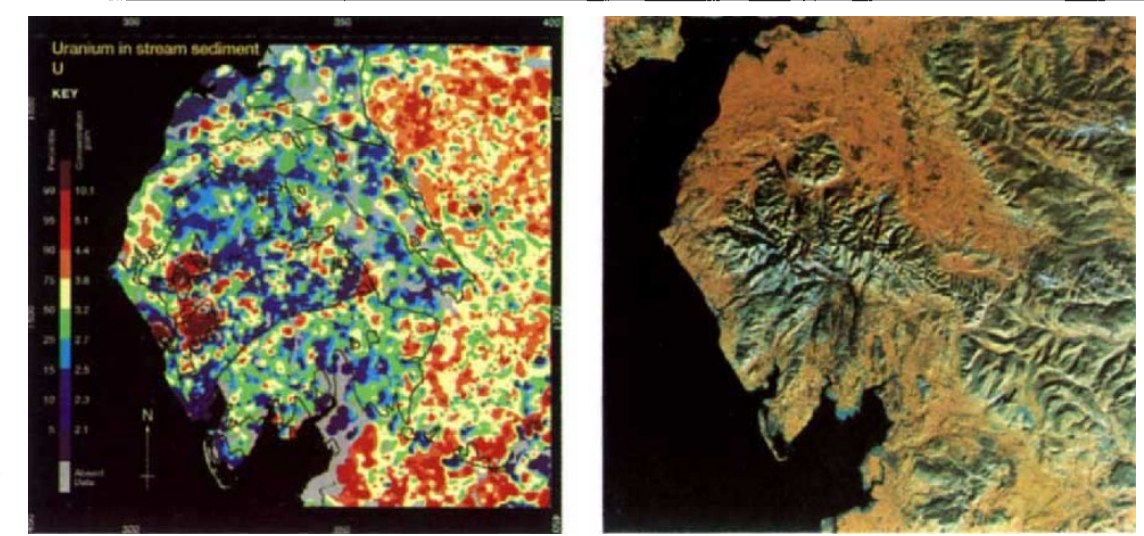

Hот streams - concentrations of uranium in stream sediments in the Lake District of the United Kingdom (left). Right, false-colour composite image of the same area using near and shortwave data acquired by the Landsat Thematic Mapper sensor. These images are taken from the most recent volume in the British Geological Survey series (Regional Geochemistry of the Lake District and Adjacent Areas), which aims to provide a systematic picture (in large format) of the geochemistry of the whole of Great Britain starting in the north and working southwards. British Geological Survey, £50. much is enough but not too much? A high-carbohydrate diet causes upregulation of the intestinal glucose transporter and physical training increases muscular and circulatory performance. This again pertains to questions of regulation at a level of organs and organism.

Regulation is a main theme in the chapters by Derek Denton and Jean Didier Vincent. When a sheep is made sodium deficient, it will within a few minutes drink the precise amount of sodium bicarbonate solution to match the deficiency, and then stop long before feedback mechanisms can take effect. The how and why addressed to physiologists include such puzzling questions as why neurohormones are generally released in a pulsatile way. The function significance of puisatility is unknown and the nature of the pulse-generator remains a mystery. We only know, for example, that shifting from pulsatile to a continuous infusion of gonadotropin-releasing hormone rapidly inhibits gonatropin secretion.

In a discussion of sensory physiology and brain function, M. Konishi emphasizes the importance of considering behaviour. The brains of owls contain neurons that respond only to sounds coming from a particular direction, and had the investigators not known about the perceptual problems the animal must solve in real life, they would not have looked for neurons selective for specific stimuli. He emphasizes that, to achieve its goal, brain sensory physiology must treat the system as a whole, perhaps the hardest hurdle to cross for neurophysiologists.

In the concluding chapter, "SelfOrganizing Systems", F. E. Yates argues that living systems are neither statedetermined nor DNA-determined. In quoting from R. C. Lewontin he calls attention to the absurdity of saying that genes have created us body and mind. "It is often said that DNA produces proteins, in fact proteins (enzymes) produce DNA . . . . Not only is DNA incapable of making copies of itself, it is incapable of 'making' anything else .... Without the protein-forming machinery, nothing can be made."

I have chosen what I perceive as a consistent message in this book, and I feel comfortable in concluding, as the editors did, that physiology will be indispensable in putting together and interpreting the masses of detailed information emanating from the revolutionary progress in molecular biology. We must detach ourselves from the infatuation with more data and more information and remember that, in the end, all the interesting molecules come from, and belong in, living organisms. of Zoology, Duke University, Durham, North Carolina 27708-0325, USA. 